\title{
Unmasking the Phenomenon of Inclusion: Parents' Perspectives on Early Childhood Curriculum
}

\author{
Adita Maharaj ${ }^{1}$ \\ ${ }^{1}$ University of Trinidad \& Tobago, Centre for Education Programmes, Tamana Campus, Trinidad and Tobago \\ Correspondence: Adita Maharaj, University of Trinidad \& Tobago, Centre for Education Programmes, Tamana \\ Campus, Trinidad and Tobago. Tel: 1-868-733-1595. E-mail: adita.maharaj@utt.edu.tt
}

Received: August 19, 2020

doi:10.5539/ies.v14n3p46
Accepted: November 16, 2020

Online Published: February 20, 2021

URL: https://doi.org/10.5539/ies.v14n3p46

\begin{abstract}
This research sought to examine the curriculum planning/implementation processes involved in the public ECCE sector in a Caribbean country. One of the focal areas was the involvement and contributions by stakeholders with respect to ECCE curriculum at public ECCE centres. In order the capture data on this area, a qualitative approach was adopted. Two (2) focus group sessions with a total of twenty (20) parents were conducted at seven (7) public ECCE centres. The study yielded compelling evidence that there was limited parental involvement as it relates to curriculum and little to no awareness of the curriculum being implemented at their children's ECCE centres. Recommendations were proffered in the form of an intensive stakeholder inclusion programme containing a myriad of strategies targeting the inclusion of parents.
\end{abstract}

Keywords: early childhood, curriculum, parental inclusion

\section{Introduction}

\subsection{Inclusion of Parents in Early Childhood Curriculum}

Early Childhood Care and Education (ECCE) is widely gaining recognition as the most critical area of importance for influencing future learning and the quality of adult life in the society. It is the period that most impressions are indeed made. This is evidenced on international, regional and local scales as governments and governing bodies place Early Childhood Care and Education as one of the determining factors in the production of a high-quality education system.

As such, enormous amounts of resources are allocated to equity, access and general reform and standardization of early childhood practice and service. This is done in a bid to ensure that children emerge from the system conversant with the demands of the twenty- first century. One key area that has undergone such transformation and standardization is the inclusion of parents in the early childhood curriculum. This area has received vast amounts of attention as schools struggle with strategies for involving parents in curricular practices. This study served to examine parental involvement in early childhood settings.

\subsection{Involving Stakeholders in the Curriculum Process}

Lindon (2012) postulates that in the early years, best practice must entail services that fully incorporate partnerships with parents and communities. Early childhood programmes must directly involve parents and community through group work and regular avenues for communication. Relationships with the important adult figures in a child's life are of central significance to young children's emotional and social well-being. This hinges on the work of theorist, Urie Bronfenbrenner, who developed the bio-ecological systems theory. He believed that child development occurs within a system of relationships emphasizing the context of a complex network of relationships of people and institutions in which the child interacts (Conkbayir \& Pascal, 2014).

Lindon (2012) further suggests that the key to partnerships with parents lies in having a network of strategies that can be utilized, so different families are taken into account. Different approaches should be used for different families with the sole aim of supporting and building on family dynamics. There are many types of parents that need to be considered. These include parents who actively work alongside their children and try to extend the learning of the child; parents who interact with staff members in early childhood settings in ways that are not congruent with developmentally appropriate practice; parents who are present in the early childhood setting but not active in the classroom; parents who basically drop their children to the school as well as attend parent 
meetings and the absent parents who do not bring their children nor have any contact with members of staff in the setting.

Successful partnerships are built on recognizing the aforementioned and employing strategies that are unique to the group and its characteristics. Guidelines for working with parents include: supporting parents, seeing yourself as a resource and support with their child's best interest uppermost and respecting all parents. Lindon (2012) also suggests the following practical strategies: ensuring your first contact is a positive one, maintaining open lines of communication taking into account differences in language and communication and avoiding educational jargon, ensuring access to information, accommodating parents' work schedules and encouraging parents to always share concerns. Equally important are recognizing the good intentions of parents, reinforcing the parents' sense of dignity and self-esteem and if applicable, as an educator, using your own experience as a parent. This research provides a basis for examining in this study the extent to which parents are involved in the curricular process and what strategies may be employed to encourage this given the context.

Barbarin, Downer, Odom, and Head (2010) intimated that neither socioeconomic status nor how prestigious the school is that a child attends determine a child's success. The best predictor of a child's success at any level of the educational system lies in the extent to which families encourage learning at home but most importantly become intimately involved in the curricular practices at school. When parents become engaged in their children's school along with home support in a nurturing environment, children develop a lifelong love of learning.

Profound changes can be witnessed in classrooms where teachers value parental involvement. Children's motivation, behavior and overall academic achievement are impacted. This is similar to the survey produced by ACF (2006) where they concluded that encouraging parent engagement is one of the best ways to create a positive learning environment for every student. Community built on parent-teacher relationships in your school correlates positively to future societal outcomes.

\section{Method}

\subsection{Sample and Methodology}

In order to fully examine whether parents are indeed included in the curricular process, a research study was conducted at seven (7) Early Childhood Care and Education (ECCE) centres in Trinidad. These centres are publicly owned and operated and cater for children three to five years old. One of the main research questions targeted was:

\section{How are stakeholders involved in the curriculum design and implementation process at the ECCE centres?}

The study employed a mixed methods approach utilizing Stake's Responsive Model of curriculum evaluation as the methodologies heavily involved the views of the stakeholders of the programme. Stake's model afforded the flexibility to explore, in a contemporary manner, the views of the persons most affected by the ECCE Curriculum. It allowed for stakeholders to share their beliefs regarding what they view the outcomes were for the programme, where the curriculum may be falling short and their inclusion in curriculum.

Two focus groups targeted a total of twenty (20) parents of the children attending the seven ECCE centres in the study. Data was gathered on:

-the parents' involvement in curriculum at the ECCE centre

-their feelings on the use and effectiveness of the ECCE curriculum

-benefits to their children

-possible gaps in curriculum planning and implementation

\subsection{Sampling Procedures}

The twenty (20) parents were chosen using purposive sampling and were drawn from the seven (7) ECCE centres in the study. This represents a population of approximately ten percent $(10 \%)$. The parents were given a consent form which provided an overview of the study and detailed the procedures to be followed by the moderators of the focus group sessions. Consent was granted by all participants in the study.

\subsection{Focus Group Procedures}

The focus group discussions were broken into two groups. Each focus group comprised a heterogeneous sample of five (5) parents from the three (3) plus group of children and five (5) from the four (4) plus group of children. They were chosen and interviewed on two separate occasions.

Each question yielded responses from the parents. 


\subsection{Data Analysis-Focus Group}

For each focus group question, the "big ideas" or "themes" discussed were summarized. Observations such as body language, tone, and opinion differences were also included in the transcripts produced. The use of concept mapping and coding were done to strengthen the qualitative data collected from the focus group. A code can be defined as a word that symbolically assigned an essence capturing or evocative attribute for a portion of language based or visual data (Saldana, 2016). Coding was used during data analysis in this study to capture the data's primary content and themes which were used to interpret, summarize, distill, and condense the data, searching for patterns. Each code was broken down into parent and child nodes using NVivo software with labels to further determine sub-categories within the data.

\section{Results}

The data from the transcripts were collected from the both focus groups after which automatic coding was done. The parent nodes based on the questions asked emerged as follows:

\section{- Awareness \\ - Strategies \\ - Inclusion}

Each of these parent nodes produce first level child nodes which assisted in categorizing the major themes for analysis and discussion.

\subsection{Awareness}

In summary, parents responded to the questions that dealt with awareness of the curriculum at the ECCE centres according to the three main themes; In house sessions, activity based and preparation for primary school. Parents indicated that they only knew that an actual curriculum existed when they attended the orientation sessions organized by the ECCE Centre in the term preceding the start of the academic year.

The discussions revealed that with respect to curriculum implementation, there were varying levels of information shared at the various ECCE centres. Approximately half of the parents shared that the curriculum document being used was shown and its contents explained with an explanation by the administrator of the methodologies utilized at the centre. The other half of the parents explained that they were told of some of the methodologies but weren't aware that an actual curriculum document existed for pre-school as it does for the primary school system. Respondents indicated that no parent sessions on the curriculum took place after this initial orientation.

Regarding the content of the curriculum document, the majority of parents revealed that they know that their children are learning through practical activities, and that their children engage in self-help skills, manners, building independence, decision making and some level of reading and writing. Some of the parents were not very expressive, two parents admitted to not being aware at all of the document. This group of parents also indicated that they believe the curriculum is getting the child ready for primary school but did mention that the perception from some of the neighboring primary schools and community members is that the children at the public centres play and 'do nothing else'.

\subsection{Strategies}

Parents were questioned on the different strategies teachers employ at the ECCE centres. NVivo categorized the responses, namely, field trips, table top activities, topics and learning centres. Parents stated that every term they are aware that there is a different topic chosen and children engage in activities connected to the topics. Some of the parents indicated that they usually look out for the ECCE centre's display of the topic web in the foyer. One group of parents suggested that they are too busy to read the webs but would question their children when they arrive home on what activities they would have engaged in for the day.

Mention was made of the use of field trips when the discussion on strategies ensued. Parents viewed the use of field trips as a teaching technique, since unlike their older children in primary school who go on general outings, they expressed that field trips at the ECCE centres are always connected to the theme being done. They expressed also that children discuss and represent what was done after the field trip. Parents also accompany their children on these trips and get first-hand observations on the questions posed to the children by the staff connected to their theme topic.

Some of the parents also shared their views on the learning centres that are set up inside the ECCE Centre. They indicated that their children often come home and explain that they did an activity at one of the learning centres. Although the parents were not able to name or list the centres, they did know that each centre has different 
categories of materials that children 'play' with in order to learn new skills. They agreed that the learning centres do not contain enough materials and children can become bored since on arrival and departure times, they often see the very same materials. They also indicated that no real attempt was made to ask parents to assist in acquiring more materials, a venture which they would willingly undertake. There was one parent who did not agree with the children spending so much time playing with the materials and the minority of the parents admitting to not having much knowledge about what goes on inside the learning environment.

The last category under 'Strategies' was table top activities. Most of the parents are familiar with the teacher facilitated table top activities that their children engage in daily. They expressed that their children will engage in their 'number and letter work' during this time. They view this routine on the schedule as the 'serious time' during the day when children would draw, colour, write, read, make art and craft items. The artifacts or products from these table top activities are normally displayed first and then sent home to parents. Approximately half of the parents intimated that not enough reading is done. They compare their children's level of work to that of children attending private school and they feel that more 'formal work' should be done. This sentiment was not echoed by all. Two of the parents indicated that children do what they are supposed to be doing for their age

\subsection{Inclusion}

The next first level node/sub theme for 'Inclusion' was demarcated as shown above. Parents vehemently suggested that they do not take part in any activity connected to the actual curriculum. They are invited to the ECCE centre when there is a field trip in order to assist in supervision of the children and to discuss transportations and fees. They are also asked to assist in any fund raining venture for the ECCE Centre. They indicated that there is always a core group of parents that will take the lead in fund raisers and the parent body is normally the source of extra funding for the centre.

They did express satisfaction and pleasure at being invited to special occasions or national celebrations such as Mother's Day, Father's Day, Carnival, Divali or Christmas. They all conveyed that it is the only time that they feel valued since the centres usually put on programmes to show appreciation and they also normally receive tokens from their children organized by staff. They also mentioned the graduation ceremony that takes place annually when they attend and help with decorations and food. It must be noted that no parent indicated that they assist in any way with the curriculum on the school's compound.

\section{Discussion}

This research question probed the involvement of stakeholders in the curriculum design and implementation process. The focus group findings provide some discussion on the awareness and involvement of stakeholders in the curricular processes. Parents indicated that the only time they were aware of the actual document in use was at the orientation sessions. This indicates that public awareness on the curriculum at the early childhood level needs to be addressed.

Although the findings show that most parents are aware of the activity- based approach, they were nonplussed on the actual contents of the document being utilized in the ECCE programme. Even when the centres attempt to do some measure of awareness of the document at the orientation sessions, the findings revealed that some centres did not include enough details on curriculum in their agenda. Notable also was the fact that there was no follow- up professional development sessions on site for parents with respect to the curriculum.

Based on the responses with respect to the actual inclusion of the parents in the curriculum at the centres, parents felt that they were included only in a supervisory capacity or for the purposes of bolstering school finances. The only other times they were included were for special occasions. As it relates to the actual implementation of curriculum, parents are not included at the centres.

Reference is made to Curtis and Carter (2008) who postulated on contemporary early childhood curriculum having five core components. One of these core components places focus on honoring families' uniqueness; delving into relationships rather than rules and building spaces that are deliberately organized to promote community. ECCE centres must adopt full inclusion of parents if these said relationships are to be built. These relationships according to Lindon (2012) must directly involve parents and community through group work and regular avenues for communication. Specific to inclusion of parents in the curriculum process, Kretzman (2010) offers a contemporary and alternative approach to community involvement. This approach is known as assets- based community development. He states that building on the strengths of the parents and utilizing these strengths to enhance and build the curriculum is paramount in early childhood programmes.

This approach highlights the importance of inquiry with respect to the skills and capabilities of these parents which according to Bruce, Meggit, and Grenier (2010) gives choice and power to the parents and wider community, 
motivating them to feel a part of the schools. Findings clearly revealed that parents are not aware and not included in the curricular processes adopted at the ECCE centres.

This inclusion of parents must be addressed in order to foster partnerships. This is integral and critical in building collegiality, trust and respect and will ultimately promote ownership of the ECCE curriculum as suggested by the research. Staff must make efforts to build this system of relationships which must include the parents in the actual day to day activities at the centres. It must be mentioned that dispositions displayed by parents in the findings suggest that they are willing to assist and if facilitated, this network of relationships can be built.

\section{Recommendations}

It is recommended that a comprehensive stakeholder inclusion programme be planned and implemented across early childhood centres. ECCE curriculum is hinged on parental involvement and thus the following recommendations are specific to the daily schedule and curricular activities observed at the ECCE centres:

1) Use parents as resources for the theme or project being done each term

2) Invite parents once a week at a stipulated period to engage in a curricular activity with a group of children

3) Organize social events with parents once per term inclusive of one Parent Appreciation event annually

4) Hold Parent Support Group meetings at least twice a term to engage in discussions specific to curriculum

5) Use the technology to keep in constant contact with the parents, for example, create parent groups on social media

6) Create an interactive Bulletin Board where parents can leave messages for the staff with issues, concerns, suggestions or even a volunteer/donation area for signing up to assist with a project or donate items

7) Utilize relevant officers/personnel at the ministerial level to assist the ECCE Centres on inclusion programmes

\section{Conclusion}

This research study sought to delve into early childhood curriculum from parents' perspectives. Research abounds on the integral value parents have on the early childhood environment. Closer examination through the aforementioned data has indeed revealed that parents are kept somewhat at arm's length from the programme. It is hoped that with the changing face of the way in which we view education and the research on inclusivity of stakeholders, that we can change practice to reflect such. Parents are wholeheartedly willing to support the process, we need just remove the masks/barriers.

\section{References}

ACF (Administration for Children and Families). (2006). Head Start performance measures center. Family and Child Experiences Survey (FACES 2000). Technical report. HHS-105-96-1912. Washington, DC: U.S. Department of Health and Human Services.

Barbarin, O. A., Downer, J., Odom, E., \& Head, D. (2010). Home-school differences in beliefs, support, and control during public pre-kindergarten and their link to children's kindergarten readiness. Early Childhood Research Quarterly, 25(3), 358-372. https://doi.org/10.1016/j.ecresq.2010.02.003

Bruce, T., Meggitt, C., \& Grenier, J. (2010). Child Care and Education. Oxford University Press. https://doi.org/10.12968/nuwa.2010.12.10.1095289

Conkbayir, M., \& Pascal, C. (2014). Early Childhood Themes and Contemporary Issues: An Introduction. London: Bloomsbury.

Curtis, D., \& Carter, M. (2008). Learning together with young children. St. Paul, MN: Red Leaf Press.

Kretzmann, J. P. (2010). Asset-based strategies for building resilient communities. New York: Guilford Press.

Lindon, J. (2012). Understanding child development: Linking theory and practice. London: Hodder Education.

Saldana, J. (2016). The coding manual for qualitative researchers (3rd ed.). Los Angeles: SAGE Publications.

\section{Copyrights}

Copyright for this article is retained by the author(s), with first publication rights granted to the journal.

This is an open-access article distributed under the terms and conditions of the Creative Commons Attribution license (http://creativecommons.org/licenses/by/4.0/). 